\title{
DILEME REGIONALIZACIJE POHORSKEGA PODRAVJA
}

\author{
Ivan Gams *
}

\section{IZVLEČEK}

UDK 911.6(497.12-18)

V planirani novi regionalni monografiji Slovenije naj bi bilo tudi Pohorsko Podravje predstavljeno v okviru mezoregij kot splet aktualnih regionalnih faktorjev in pri submakroregijah historixni nastanek regionalnih prvin.

\section{ABSTRACT}

UDC 911.6(497.12-18)

REGIONALIZATION OF THE POHORSKO PODRAVJE - SOME DILEMMAS

Dilemmas of the regionalisation of the mountainous part of the basin of the Drava(Pohorsko Podravje).

In the planned new geographical monograph of Slovenia, also the Pohorsko Podravje shoud be represented in frame of mezoregions as a complex of actual regional factors, and in frame of submacroregions the genesis of the regional elements mostly.

Dileme regionalizacije Pohorskega Podravja so izvedbene in naCelne narave. O naðelih delitve zemeljskega ozemlja smo se na mnogih sestankih razgovarjali v okviru sodelavcev nove regionalne geografske monografije Slovenije, to je pri nacrtu, ki je po splošnem mnenju poglavitna naloga slovenskih geografov $\mathrm{v}$ naslednjem obdobju.Pri tem se je pokazalo, da imamo sicer kar obilno regionalnogeografsko literaturo o naši deželi, nimamo pa iste koncepcije, ce izvzamemo pavšalno trditev o povezovanju naravnih in družbenih dejavnikov v pokrajiniske splete. Del naših geografov zagovarja prakso naših geografov- "klasikov", to je Antona Melika in Svetozarja Ilesica. Njuna koncepcija o delitvi Slovenije pa je različna. Kot primer si oglejmo njuno delitev Pohorskega Podravja.

A.Melik tudi $\mathbf{v}$ našem primeru ni bil dosleden pri imenovanju regij. V knjigi Slovenski alpski svet (Melik,1954,s.9) skica, ki ima podpis Slovenski alpski svet, vključuje Pohorsko Podravje in ga deli na naslednje enote: Pohorje, Kobansko, Strojna, Mislinjska dolina. V sledeci knjigi Štajerska s Prekmurjem in Mežiško dolino (1957) opisuje Pohorsko Podravje najprej kot celoto, nato sledijo poglavja z naslovi Pohorje, Kobansko, Dravska dolina, Mežiska dolina, Mislinjska dolina, Vitanjsko podolje. Opis gorovij je precej daljši kot opis dolin, saj tu obravnava predvsem le dolinske kraje. Pri njih pa je bil tu in tam prisiljen, ponoviti že povedano, ako to predstavlja pomembne vezi med dolino in hribovjem. Skice $\mathrm{z}$ mejami regij v tej knjigi ni.

* Dr, red. univ. prof, Oddelek za geografijo, Filozofska fakulteta, Aškerčeva 12, 61000 Ljubljana, Slovenija 
S. Ilešix $(1967,1979)$ je tudi v primeru Pohorskega Podravja ubral dvojno, naravnogeografsko in družbenogeografsko delitev ozemlja. Kot okvir družbenega življenja ohranja fiziognomske regije t.im.severovzhodne slovenske predalpske pokrajine. To so tradicionalne orografske enote Pohorje, Podravsko obmejno hribovje (Kozjak in Košnjak), Strojna, Vzhodne Karavanke, Vitanjsko-konjisko hribovje. Pri družbenogeografski delitvi so nosilke regijskega imena doline, Dravska, Mežiška in Mislinjska, toda ne v obsegu njenih rek, temvex jih na karti omeji na obseg obx̌in. Dravska dolina se tako konđa ob vzhodni meji radeljske občine in na primer okolica Šentlovrenca je z vsem obsežnim pohorskim pobočjem vred pridana "pravim subpanonskim pokrajinam". Ker so pri Ilešicu regije samo nakazane, ni razvidno, katero snov je avtor predvidel $\mathbf{v}$ okviru opisa naravnogeografskih in kaj $\mathbf{v}$ okviru družbenogeografskih regij. Zato tudi ni mogoče presoditi, ali gre za dualistið̌no geografijo. To bi od zagovornika enotne, to je kompleksne geografije tudi težko pricakovali (gl.Ilešič, 1967,1979).

Pri razgovorih o koncepciji nove regionalne geografije Slovenije se je večina zavzemala za eno samo regionalizacijo, pri cemer so bile dileme, ali ozemlje primarno deliti na naravne ali družbenogeografske regije. Nekateri so zagovarjali mnenje, da je regionalizacija sama po sebi poglavitni namen regionalno geografske analize. $\mathbf{S}$ tem in $\mathbf{s}$ trditvijo o eni sami regionalizaciji pa so privedli diskusijo $\mathrm{v}$ slepo ulico, ker so zamenjali cilj regionalne analize $\mathrm{z}$ metodo dela. Posamezne pokrajinske prvine prostorsko postopno prehajajo $\mathrm{v}$ druge in prehodi so le redko ostri. Tako je tudi z t.i. regionalno strukturo, ki jo pokrajinske prvine oz. pokrajinski dejavniki sestavljajo. Znacilnosti ene strukture pocasi prehajajo $\mathbf{v}$ znacilnosti druge in le redkokje so stiki ostri. Regijo cesto definiramo kot ozemlje $\mathrm{z}$ bolj ali manj homogeno regionalnogeografsko sestavo (strukturo), ki da je enkratna in na zemeljskem površju neponovljiva. Pri ugotavljanju te sestave pa ne gre le za sestevek pokrajinskih dejavnikov, ampak tudi za razmerje med nadrejenimi in podrejenimi dejavniki, kar se prav tako spreminja. Na primer ravnina je $\mathrm{v}$ okviru Slovenije močan dejavnik hitre rasti prebivalstva, $\mathrm{v}$ nasprotju $\mathrm{z}$ depopulacijo hribovja in gri夭evja. Nekatera predmestja pa hitro rastejo tudi v robnem griðevje in negirajo posplošno trditev. Ponekod prebivalstveno nazadujejo tudi dolinski kraji. Skratka, regionalna struktura je zelo heterogena. Dolgotrajne diskusije o bolj in manj pomembnih dejavnikih so bile pri snovanju monografije včasih nepotrebne, ker je število pokrajinskih faktorjev in njihova dominanca od primera do primera razlixno. Regionalno strukturo mora ugotoviti vsak analitik regije sam. Pri tem pa je \kodljivo apriorno zapostavljanje fizǐ̌nogeografskih ali družbenogeografskih dejavnikov, kar je pogosta hiba nele nasih, ampak tudi tujih regionalnih geografij.

Zdi se, da omogoca bolj neosebno in tudi bolj kvantitativno obravnavo moderna metoda analize pokrajine s pomoxjo vnosa mnogih geografskih prvin $\mathbf{v}$ kvadratno omrežje in izračuna njihove medsebojne prostorske korelacije s pomočjo računalnika. Ta nova metoda omogoča obravnavo veliko vex prvin kot stara metoda prikrivanja na prozorni papir narisanih tematskih kart, pri katerih izstopajo obmox ja sovpadanja mnogih prvin. V našem geografskem slovstvu je po novi metodi obdelanih že nekaj predelov, ki jih vneti zagovorniki sistemske teorije radi spregledajo. In to neupraviceno, saj kvantitativno opredeljuje to, kar sistemska teorija 
samo teoretsko nakazuje. Žal pa te računalniške analize ne moremo zahtevati od vseh sodelavcev, tudi zato, ker je prezamudna. Ni pa ta metoda tako objektivna kot se proglaša. Subjektivna ostaja pri vnašanju vhodnih podatkov, pri številu upoštevanih prvin itd., tudi pri delitvi prvin na njihove sestavine. Relief lahko vnesemo kot enotno kategorijo (ravnina, gricevje, hribovje), lahko pa ga razdelimo npr.še na dolžino slemen in dolin, strmino in nadmorsko visino in nato za vsako sestavino posebej izracunavamo korelacijske koeficiente. Kot njihov seŠtevek dobi relief večji pomen kot sicer (prim. Perko, 1989).

Druga hiba te nove metode je ista, kot pri starejši regionalni geografiji. S tem, ko ugotovimo prostorsko sovpadanje dveh pokrajinskih prvin, je ponekod dokazana njuna genetska zveza, drugod je le nakazana ali pa je sovpadanje slučajno. Zniževanje letnih povprečnih temperatur $\mathrm{z}$ rastočo nadmorsko višno je genetsko utemeljeno s splošno klimatsko teorijo. Novodobno zmanjక̌vanje prebivalstva $\mathrm{v}$ vec jih višnah cesto tudi sovpada $\mathrm{z}$ rastoč nadmorsko viß̌ino, ni pa visok korelacijski koeficient dovolj za iskanje razlogov v konkretnih primerih, ker se ljudje izseljujejo zaradi stevilnih vzrokov. Takih nasilnih genetskih razlag iz sovpadanja dveh dejavnikov, na primer stevila delovnih mest $\mathrm{z}$ rastjo prebivalstva, pa je najti pri mnogih geografih, zlasti pri tistih, ki vidijo v proucevanju razvoja in procesov poglavitno nalogo geografiije. Žal je naša stroka pri tem omejena in je preprixljiva samo pri iskanju prostorskih sovpadanj dveh ali več pojavov. Imamo pa prednost, da lahko nakažemo več dejavnikov, ki morejo vplivati na spremembe. Pri prostorskih pojavih je množica razlienih pozitivnih in negativnih dejavnikov kar običjna. Primer Zidanega mosta morebiti najbolj zgovorno prica, da je potrebnih za rast naselja mnogo vec kot en sam dejavnik - promet.

Nedvoumno in dokončno shemo regij za vso deželo zahtevajo mnogi §olniki. Pri tem je prišlo veasih do zamenjave sredstva s ciljem.V pokrajinah imamo opraviti z že nakazano pestrostjo in raznolikostjo geografskih dejavnikov, ki je $\mathbf{v}$ se tako obsežnih knjigah ne moremo v celoti prikazati. Nujno smo prisiljeni k shematizaciji, to je izdvojitvi obmocij, rajonov in regij, v okviru katerih prezremo lokalna odstopanja in se omejimo na glavne znacilnosti. Te dajejo pečat regionalni strukturi, ki je s tem zavestno poenostavljena. V knjigah nove regionalne geografije bo dovolj prostora za prikaz raznolikosti tudi s pomoxjo že znanih geografskih metod, kot so izdelava tematskih kart za važnejše dejavnike, tipizacija, rajonizacija itd. (Gams, 1984).

Po diskusijah o novi regionalni monografiji je nastala kompromisna shema precej velikih makroregij, ki jih naj nato sodelavci delijo na mezoregije in mikroregije. Taka makroregija je v našem primeru Pohorsko Podravje.

V nadaljnem je prikazan poskus, kako deliti gorato ozemlje na naravnogeografske in gravitacijske (nodalne) enote in obenem ohraniti princip ti. kompleksne geografije. Poskus ohranja tudi $\mathbf{v}$ ljudski rabi in $\mathbf{v}$ starejsi geografiji uveljavljene orografske enote kot sta Pohorje in Kozjak. Želimo se izogniti cerem dvojne delitve, ki je v naslednjem. Če Pohorsko Podravje delimo le na dolinske regije, med drugim izgine Pohorje, o katerem obstoji obsežna literatura 
(med drugimi Hilt1,1893, Koprivnik,1913-1919) in mnogi pomembni podatki, izračunani v njegovem okviru (tudi Gams, 1959). Če ga delimo le na gorstva, izginejo doline, o katerih prav tako obstojijo geografske monografije (za Mežiško dolino Medved, 1967, za Dravsko Zgonik, 1977, v njenem okviru v novejక̌sem casu za radeljsko občino - Radlje skozi cas) Vprašanje za Pohorsko Podravje kot tudi za vse predalpsko hribovje je, katero snov obravnavati pri hribovjugorovju in katero $\mathrm{v}$ okviru dolin, ki s svojimi poboxji zajemajo tudi hribovje in gričevje, tako da se snov ne bi ponavljala.

Predlagamo, da so osnovne mezoregije - glavne doline. V njih prebiva večina prebivalcev. Gricevja in hribovja zazvzemajo res veliko vecino ozemlja, toda $v$ njem je majhna gostota naselitve, $\mathbf{v}$ nasprotju $\mathrm{z}$ dolinskimi kraji, kjer se prebivalstvo že vso postfevdalno dobo hitro povecuje. V letih 1856-1910 so koroski dolinski kraji napredovali za skoraj 2/3, gorati pa nazadovali za $4 \%$ ( Gams, 1959, s. 175). Po š ne objavljeni oceni je v koroski regiji 1.1981 bila gostota prebivalstva na ravnem dnu dolin med 400 in 500 , na vzpetinah pa le okoli 27 preb./km2. (vkljuceno je hribovje nad mejo agrarne naselitve ). Prebivalstvo na ravnem dnu Mislinjske doline se je $\mathrm{v}$ letih 1961-1989 povecalo na indeks 133, na vzpetem svetu pa padlo v obmoxju Centralnih Alp na indeks 87 in v Karavankah na 86. Ravninski svet pomeni pedološko, hidrološko, skratka ekološko enoto. Njegovo prebivalstvo pa se je $\mathrm{v}$ veliki meri naselilo $\mathrm{z}$ okoliških hribov in je na te hribe se v marsiŁem navezano.

V okviru dolinskih mezoregij bi obravnavali vse, kar neposredno pomembnejకe vpliva na regionalno strukturo. $\mathbf{Z}$ besedo "neposredno" je mišljen aktualni vpliv $\mathbf{v}$ smislu prostorskih soodvisnosti geografskih dejavnikov. Posredni ali drugotni vpliv izhaja iz geneze prvin. V tem smislu npr. geotektonska struktura ne pomeni neposrednega vpliva, ker vpliva na človeka sele preko zvez litologija-prst-raba tal-agrarna geografija- naselja.Relief neposredno vpliva $\mathrm{z}$ naklonom povrక̌ja, nadmorsko višino, obsegom enote in podobno, ne pa s samo morfogenezo. Pri ugotavljanju regionalne strukture upoštevamo sedanje prebivalstvo, njegovo zaposlitev, starostno sestavo in podobno, ne pa njegovega Casovnega razvoja oz. zgodovine. Historixna oz. genetska plat je torej $v$ tem smislu posredni ali drugotni faktor. Genetske razlage, ceprav niso neposredno osnovne za geografske strukture, naj bi obravnavali v okviru makroregij ali njenih submakroregij. Potrebne so, ker to zanima ljudi in ker se z njimi ukvarja delno tudi geografija.

Po mojem mnenju sta na Pohorskem Podravju prisotna dva osnovna pokrajinska tipa, ravnina in vzpeti svet. Oba je potrebno obravnavati znotraj mezoregij. Skupni makroregionalni opis naj vsebuje predvsem geološki, reliefni, hidrološki, pedološki, vegetacijski razvoj do sedanjosti, pregledno pa tudi npr. klimo. Lokalna odstopanja od te sheme so predmet obravnave po mezoregijah. Iz družbene sfere naj se $\mathbf{v}$ okviru makroregij poda zgodovinski razvoj v polnem pomenu besede (razvoj prebivalstva, naselij, prometa, gospodarstva vobče, arheologija ipd.). Tu naj bodo podane znacilnosti, ki veljajo za vse ali več mezoregij. 
Porazdelitev snovi na makroregije, mezoregije in mikroregije ni mogoce shematsko predvideti, ker so razlike od primera do primera . Za dolino, ki nima ali ni nikoli imela vremenska postaje, pri klimi mezoregije ne bo mogoce dodati kaj bistveno veð kot bo povedano v okviru makroregije. Podobno velja za reliefne, litološke, naselbinske idr. pokrajinske prvine. Pedološke in vegetacijske razmere in pogoje za vodno oskrbo kaže v večji meri prenesti na mezoregije, saj bolj vplivajo npr. na agrarno geografijo kot na primer razvoj vodne mreže. Pomemben vpliv lege ozemlja, ki ga v geografiji pogosto prezremo, je smiselno prikazati v okviru makroregije in mezoregij.

V okviru dolinske mezoregije bi glavne podatke števiľno ugotavljali tudi $v$ okviru njenih mikroregij, kot so ravnina, gricevje in hribovje. Iz teh podatkov bo mogoce napraviti tudi kvantitativni pregled za hribovito, grixevnato in ravninsko submakroregijo in makroregijo $\mathbf{v}$ celoti. Poudarjam pa, da ni smiselno, monografijo natrpati s preobilico steviľnih podatkov, zlasti ne takih, ki se Casovno hitro spreminjajo.

Iz nakazanih smernic predlagano delitev ozemlja Pohorskega Podravja prikazuje priložena skica. Izdvojitev Mežiske in Mislinjske doline v glavnem ne vzbuja veðjih dilem, ako ju omejimo na porečje. Visokogorske skupine Olševa, Peca in Uršlja gora bosta genetsko temeljiteje prikazani celo v drugi knjigi - o Severozahodni Sloveniji. Koněni tok Meže je v Mislinjski dolini, ki sega do Dravske doline. Njen spodnji konec je zdaj v občini Dravograd. Vendar je tamkajక̌nje nekmetijsko gospodarstvo vezano na stik vseh treh dolin. Drugi razlog neupoštevanja sedanjih obcinskih meja je verjetnost, da bo kmalu prišlo do razbitja sedanjih prevelikih obð̌in in do obnovitve stare občine Šentjan(ž). Več dilem je pri Dravski dolini, ki jo soteske lox̌ujejo v več mikroregij. Prva obsega (zgodovinsko) koroški del doline med Libelixami in Vrati, druga Mučko kotlino, tretja ruško dolino, glede katere se zastavlja dilema njenega obstoja in omejitve do Maribora oz. Dravskega polja. Če ostale mezoregije Pohorskega Podravja vkljucujejo dolinski terasasti svet in zaledno hribovje, potem moramo tudi poboxja Pohorja in hribovja Kozjaka pridružiti dolinski regiji, ki je v našem primeru Ruška dolina med Falo in Bresternico oz. Bistrico.

$\mathrm{Ob}$ istem principu se odpira dilema o mezoregionalni pripadnosti jugovzhodnega Pohorja in severnih pobočij ti. Vitanjskih Karavank. Po Ilešicu (1979) pripada z vsem poreð̌jem Savinje in s slovenskokonjisko obð̌ino vred savinjski makroregiji. Tako mnenje bi lahko zagovarjali tudi $\mathbf{z}$ odhajanjem na delo $\mathbf{v}$ Velenje iz Doliða in iz Vitanja $\mathbf{v}$ Savinjsko dolino ter pripadnostjo konjiski obðini. Ne gre pa zanikati, da so razvodni apneniški hrbti Paškega Kozjaka, Stenice in Konjiške gore pomembna fizið̌no geografska in družbena meja, ki se je držijo mnoge upravne meje. Nekdaj so bile tu meje upravnih obđin in verjetno bo tako tudi po prihodnji reorganizaciji obđin.Razbitje Pohorja po razvodnici bi pomenilo, da bi pripadal savinjski regiji med drugim rojstni kraj Jurija Vodovnika, ljudskega pesnika Pohorja - Skomarje, in pohorski turistični center Rogla. 
Zaradi že nakazane potrebe po kontinuiranosti geografije, iz makroregije Pohorsko Podravje ne kaže izločiti jugovzhodnega pohorskega pobočja, ki gravitira proti Dravinjskemu gričevju, Dravskemu polju in Mariboru in bo pripadlo tamkajsjim podgorskim mezoregijam. Meje Pohorja je iskati na stiku s prigorskim griðevjem, ki ga ponekod obeležujejo vinogradi in terciarne kamnine. Če bo tudi ta del Pohorja bolj ali manj kvantitativno opredeljen kot mikroregije omenjenih mezoregij, ne bo težko s temi podatki zgraditi podobo Pohorja. Ob tem naj izrazim misel, da marsicesa v regionalni geografiji (se) ni mogoce številcno opredeliti in da ima trajnejŁo vrednost nazoren strokovni besedni prikaz kot pa minljivi statistiðni podatki.

Ob sedanjem kolektivnem snovanju nove regionalne monografije moramo račnati, da bodo mnogi statistiðni podatki, potrebni za izdelavo rokopisa, ob objavi knjige o Severovzhodni Sloveniji zastareli za desetletje ali vec. Pricakovati je, da bodo vecja mesta, občine in doline tudi $v$ bodoce, poleg statisticnih publikacij, objavljale novejše statistiðne podatke v enaki meri kot zdaj. Saj premoremo mnogo monografij za vecje kraje v dolini (Slovenjska Bistrica, Ruse, Dravograd, Ravne na Koroßkem, Slovenj Gradec, pretežno etnografsko knjigo o Vitanju), in celo za hribovski kraj Strojna (Makarovix, 1982). Seveda se ne moremo odpovedati kvantitativnim podatkom o regionalni strukturi, najmanj pa ti. minimalnim pokazateljem.

Odprto je tu kot drugod vprašanje vključcevanja zamejskih krajev v novo geografsko monografijo. Zdi se mi smotrno, da pri fiziěnogeografskem orisu pri marsikateri snovi sežemo preko državne meje, tako da bi predstavili kot celoto npr. Kozjak,Košenjak (kot del Golice), Strojno ipd. Za enakovredno obravnavo zamejskega dela $v$ okviru družbene geografije pa vsaj za našo makroregijo ni dovolj primernih podatkov. To se ne pomeni, da osnovne poteze ne bi mogli nakazati $\mathrm{z}$ besedo.

Potem ko vemo za obseg makroregije, laže razpravljamo o njenem imenu. Ime Pohorsko Podravje je $v$ geografski literaturi sicer že udomađeno, ni pa povsem logično. Ozemlje sega preko razvodnice $\mathrm{v}$ porečju Savinje $\mathrm{v}$ dolisko-vitanjskem podolju in $\mathrm{z}$ delom Završ ter Razborja. Za prvi člen v sestavljenem imenu, "Pohorsko" (Podravje) govori dejstvo, da pripada Pohorju polovico ozemlja. Toda Pohorje je na eni strani edino hribovje, ki se, poleg Karavank, dviga ‘ez mejo agrarne naselitve, na drugi strani pa je $v$ njem le znaten delež griðevja $v$ metamorfnih in terciarnih kamninah. Mogli bi pridevnik "pohorski" imeti za oznako centralnoalpskega reliefa, ki mu pripada $3 / 4$ vse makroregije. Ob njem je na Pohorskem Podravju okoli 1/5 ozemlja zgrajenega iz razlixnih terciarnih kamnin. $\mathrm{V}$ njih prevladuje griðevje, ki sega ponekod tudi na robne metamorfne kamnine.

Vidim predvsem tri imena $\mathrm{z}$ manj lepotnimi napakami : gorata Severovzhodna Slovenija (kot nasprotju nižinskemu Podravju) ali, po Ilesič, severovzhodno predalpsko hribovje. Žal pa sta obe imeni predolgi in nimata izgleda, da bi se uvaljavili v javnosti. Zato $v$ tem clanku ostajam pri uveljavljenem Pohorskem Podravju. Tretja možnost je Gorato Podravje, ki je rahlo preohlapno a od vseh se vedno najbolj točno, v upanju, da pri besedi ne bi pomislili na Podravje v Avstriji. 
Podobna netǒ̌nost o obsegu ozemlja se drži t.i. koroške regije.S tem je navadno mišljena skupnost občin Ravne,Slovenj Gradec, Dravograd in Radlje. Njihovo ozemlje je v srednjem veku res bilo v okviru koroških fevdalnih tvorb, ki so zapustile sedanji, nekoliko stajersko modificirani koroski dialekt na ozemlju zahodno od crte Dolic-Rogla-Fala-Selnica- Box (Kozjak),kar je skoraj 2/3 naše makroregije. Toda v novem veku je Korołka obsegala le Mežiško in Dravsko dolino navzdol do Vrat vzhodno od Dravograda. Ime koroška regija samo po sebi ne izključuje avstrijske Korołke. Odpade tudi ime jugoslovanska korołka regija, ki je z izrazom slovenska koroska regija spet ne kaže nadomestiti. Morebiti bi bolj ustrezalo ime zgornjedravska regija, seveda, ako bi imelo upanje, da izrine že dokaj uveljavljeni izraz koroška regija.

\section{LITERATURA IN VIRI}

Gams,I.,1959, Pohorsko Podravje.Razvoj kulturne pokrajine. Dela 5 Geografskega inštituta SAZU,Ljubljana.

Gams,I.,1984,Metodologija geografske členitve ozemlja. Geografski vestnik,55,Ljubljana.

Hilt1,C.,1893, Das Bachergebierge. Klagenfurt.

Ilesic,S.,1967, Severovzhodna Slovenija in njena regionalna razclenitev. ČZN,N.v.,(38),3, Maribor.

Ilešix, S.,1979, Pogledi na geografijo.PK,Ljubljana.

Koprivnik,J.,1913-1919, Pohor je (Ponatis iz Planinskega vestnika). Maribor - Ljubljana.

Makarovic,M.,1982, Narodopisna podoba koroßke vasi. MK, Ljubljana.

Melik,A.,1954, Slovenski alpski svet.SM,Ljubljana.

Melik,A.,1957, Štajerska s Prekmurjem in MežiŠko dolino. SM, Ljubljana.

Medved,J.,1967, Mežiška dolina. MK, L jubljana.

Perko,D.,1989, Vzhodna Křka kotlina in njena pokrajinska sestava. Geografski zbornik XXIX, SAZU, Ljubljana. Radlje skozi Cas.Radlje(brez letnice).

Zgonik,M.,1977, Dravska dolina. Obzor ja, Maribor.

\section{REGIONALIZATION OF THE POHORSKO PODRAVJE - SOME DILEMMAS}

In the plans of a new geographical monograph on Slovenia, the question still remains as to which subject matter should be included into the chapter on mezoregions and which one into the chapter on submacroregions. The author supports the idea that mezoregions should be mainly presented as a complex of regional factors which affect the arrangement of geographical phenomena in space. The genetic point of view (morphogenesis, social history, etc.) should be mostly presented under submacroregions. In the case of the Pohorsko Podravje, the former are names upon the main valleys, and the latter upon the mountains and hills. It would also be reasonable to include a certain part of the subject matter, which is important for the 
regional complex on a larger area, into the description of submacroregions.

Such sheme could be used for all Slovene regions where intense concentration of population only occurs in one part of a macroregion.

The article explains the regionalization of the Pohorsko Podravje shown on the sketch. The latter demostrates the following submacroregions: the Pohorje, the Kozjak (with the Kosenjak massif), the Strojna - Gmajna ridge ( hills of Ravne), the Kotlje syncline (lowland), the Karavanke high mountains, and the Karavanke hills; and the following mezoregions : the valley of the Drava, Meža and Mislnja rivers, and the syncline valley of Vitanje.

Divisions of a submacroregion - within the frame of a mezoregion - represent microregions. If these microregions are studied from the quantitative aspect, the sum of these items of information gives, in some regards, the quantitative regional structure of a submacroregion. 


\section{Regionalizacija Pohorskega Podravja}

Regionalization of the Pohorsko Podravje.

Mezoregije - mezoregions : I - Dravska dolina - the Drava Valley; II- Mislinjska dolina - the Mislinja Valley; III Vitanjsko podolje - the Vitanje Lowland; IV- Mežiška dolina - the Meža Valley.

Submakroregije - Submacroregions : 1 - Kozjak (1a Kozjak; 1b - masiv Košenjaka - the Kosenjak Massif); 2 - Pohorje - the Pohorje; 3 - Hrbet Stojna - Gmajna (Ravenski hribi)-the Ridge of Strojna - Gmajna (Hills of Ravne) ; 4 - Hotuljsko podolje - the Kotlje Lowland; 5 - Visokogorske Karavanke - the Karavanke High Mountains; 6 - Sredogorske (Vitanjske) Karavanke - The Karavanke (Vitanje) Hills.

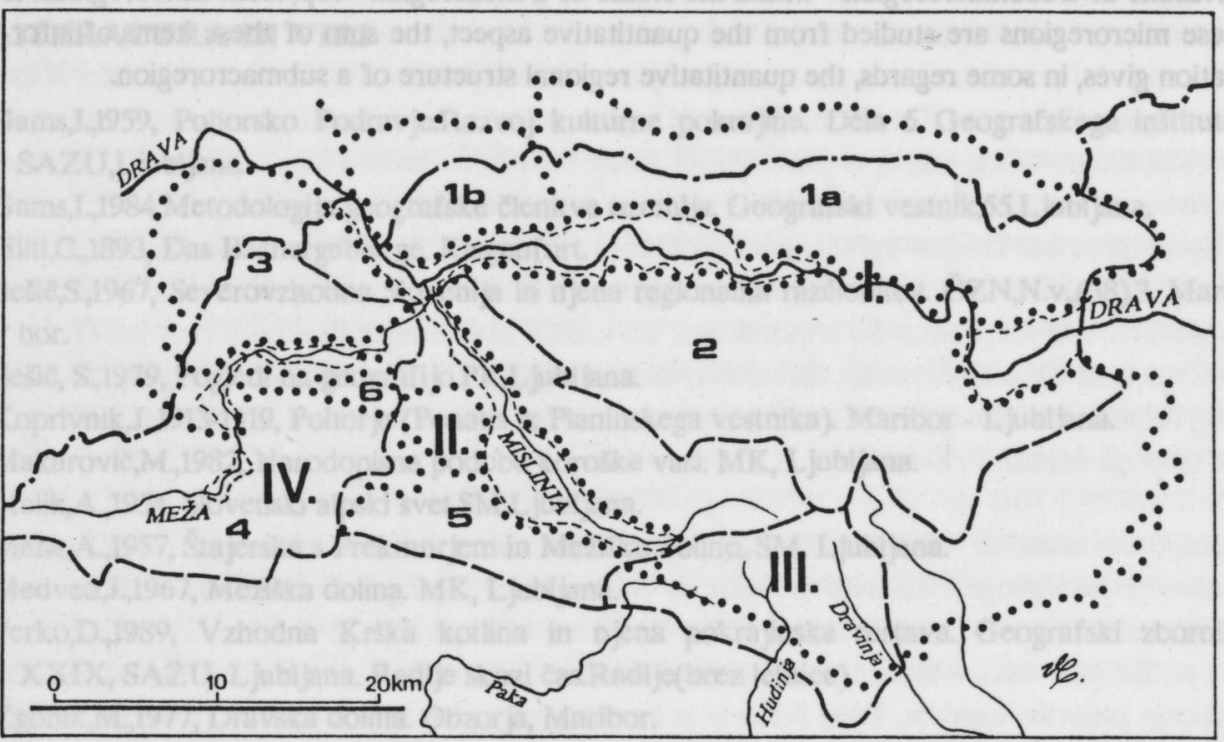

$1 \bullet \bullet \bullet \bullet \bullet$

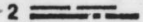

3 